\title{
OBTENÇÃO DE DADOS DE EQUILÍBRIO DE SISTEMAS AQUOSOS BIFÁSICOS FORMADOS POR POLIETILENOGLICOL E FOSFATO DE POTÁSSIO
}

\author{
O. R. R. GANDOLF ${ }^{1 *}$, G. R. F GONÇALVES ${ }^{1}$, J. G. PIMENTEL ${ }^{2}$, D. M. BASTOS ${ }^{3}$, R. C. I. \\ FONTAN $^{4}$ R. C. F. BONOMO ${ }^{4}$ \\ ${ }^{1}$ Universidade Estadual do Sudoeste da Bahia, Mestrando em Engenharia e Ciências de Alimentos. \\ ${ }^{2}$ Universidade Estadual do Sudoeste da Bahia, Mestranda em Ciências Ambientais \\ ${ }^{3}$ Universidade Estadual do Sudoeste da Bahia, Graduando em Engenharia de Alimentos \\ ${ }^{4}$ Universidade Estadual do Sudoeste da Bahia, Departamento de Tecnologia Rural e Animal \\ *e-mail: olga.gandolfi@hotmail.com
}

\begin{abstract}
RESUMO
A extração líquido-líquido utilizando sistemas aquosos bifásicos (SABs) é uma técnica promissora na purificação de biomoléculas de interesse industrial e laboratorial. Para a purificação de compostos utilizando $\mathrm{SABs}$ é imprescindível a obtenção dos dados de equilíbrio nas condições de partição. Diante disso, objetivou-se nesse trabalho a construção das binodais para sistemas aquosos bifásicos compostos por polietilenoglicol 6000 g.mol ${ }^{-1}$ (PEG 6000), fosfato de potássio e água, nos pHs 6 e 7, na temperatura de $5^{\circ} \mathrm{C}$. O efeito do $\mathrm{pH}$ nas curvas binodais foi analisado, sendo observado uma diminuição da área bifásica com a diminuição do $\mathrm{pH}$. Verificou-se ainda que a elevação do pH aumentou o comprimento da linha de amarração (CLA), e diminuiu a inclinação (ILA). Foi possível a obtenção dos dados de equilíbrio do sistema PEG/fosfato nas condições estudadas.
\end{abstract}

\section{INTRODUÇÃO}

Nos últimos anos, a extração líquidolíquido utilizando sistemas aquosos bifásicos (SAB's) tem apresentado um grande potencial para a concentração, isolamento e separação de biomoléculas. Os SAB's são misturas ternárias, compostas majoritariamente por água, (70\% a 90\%), que sob determinadas condições de composição, temperatura e pressão, apresentam duas fases em equilíbrio termodinâmico. As fases são regiões que apresentam propriedades termodinâmicas intensivas diferentes, como índice de refração, composição e densidade. Mas, quando as duas fases do SAB's estão em equilíbrio, nenhuma propriedade termodinâmica varia em uma dimensão temporal, ou ainda, não há troca resultante de matéria entre as fases. Essas fases são separadas por uma interface, que é uma região na qual as propriedades termodinâmicas intensivas de cada fase transitam para valores diferentes, sempre tendendo para o valor daquela propriedade no seio da outra face em equilíbrio (CARVALHO et al., 2007).

A formação de duas fases durante $o$ processo de mistura de soluções aquosas dependerá das interações intermoleculares expressas em termos de energia livre - entre os constituintes formadores do sistema. Serão também estas mesmas interações as responsáveis por todas as propriedades físicoquímicas presentes nas duas fases, como por exemplo, a distribuição dos diferentes componentes do sistema, da relação de volume entre as fases, da diferença de potencial elétrico, do excesso de energia livre 
associados à interface, do coeficiente de partição de um soluto específico, entre outros (DA SILVA E LOH, 2006).

Os SAB's podem ser formados a partir da mistura de dois polímeros, de polímero e sal, (GARZA-MADRID et al., 2010), de solvente orgânico e sal (AMID et al., 2012) ou de líquido iônico e sal (LOUROS et al., 2010). Os sistemas PEG e sal apresentam vantagens em relação aos demais sistemas pelo custo reduzido, menor tempo de separação de fases e propriedades físicas favoráveis à operação em larga escala, como elevada seletividade e diferença de densidade e viscosidade entre as fases, adequadas para o trabalho com equipamentos de extrações disponíveis no mercado. Além disso, os sistemas PEG e sal têm sido muito utilizados para a extração de compostos pelo fato de poderem ser formados à temperatura ambiente. A separação das fases é atingida mais rapidamente em virtude da menor densidade da fase salina em relação à fase polimérica, o que facilita a aplicação de sistemas formados por polímero-sal em escala industrial (HUSTED et al., 1985; SALABAT, 2001).

Para a utilização dos SABs é imprescindível o conhecimento do comportamento das fases nos sistemas. Para isso, são obtidos os diagramas de fase para os componentes, nos quais as composições dos constituintes para a separação de fases são determinadas (SAMPAIO, 2011). Os dados de equilíbrio de fases dos SABs podem ser representados em diagramas de equilíbrio, em temperatura e pressão fixa. Os diagramas de equilíbrio representam graficamente a composição dos constituintes do sistema, presentes em certas concentrações, onde ocorre a separação de fases.

A curva que divide a região em duas fases é chamada de binodal. A binodal determina os pontos de máxima composição em que um sistema permanece unifásico e representa a composição das fases superiores e inferiores de uma determinada linha de amarração (LA). As linhas de amarração são representadas como as retas que ligam os pontos no diagrama que representam a composição das duas fases em equilíbrio. Quaisquer pontos que pertençam à região bifásica e estejam na mesma linha de amarração terão as mesmas propriedades termodinâmicas intensivas (volume molar, densidade, entalpia molar etc.), porém sendo distintas as variáveis extensivas (massa, volume etc.) (DA SILVA E LOH, 2006).

Ao se fazer um estudo da partição é necessário conhecer os dados de equilíbrio dos sistemas que serão utilizados. Para cada sistema seja polímero/polímero, polímero/sal polímero/líquido iônico existe um diagrama de fases que define as proporções entre os componentes formadores das fases. Alguns já estão disponíveis na literatura, porém, é importante ao testar um novo sistema que se construa um diagrama nas condições de trabalho a serem utilizadas na extração (temperatura, massa molar do PEG, $\mathrm{pH}$, entre outros).

Diante do exposto, objetivou-se nesse trabalho estudar o comportamento do sistema de duas fases constituídos por fosfato de potássio e polietilenoglicol $\left(2000 \mathrm{~g} \cdot \mathrm{mol}^{-1} \mathrm{e}\right.$ 6000 g.mol ${ }^{-1}$ ) e água na temperatura de $5^{\circ} \mathrm{C}$.

\section{MATERIAIS E MÉTODOS}

\subsection{Materiais}

O trabalho experimental foi realizado no Laboratório de Engenharia de Processos da Universidade Estadual do Sudoeste da Bahia, campus de Itapetinga. Os reagentes utilizados na condução deste trabalho foram: fosfato de potássio monobásico e fosfato de potássio bibásico (P.A. - Cinètica, Brasil) e polietilenoglicol 2000 g.mol ${ }^{-1}$ e 6000 g.mol ${ }^{-1}$ da Synth, Brasil. 
Nos experimentos foram empregados água destilada e todos os reagentes usados foram de grau analítico.

\subsection{Métodos}

\subsubsection{Preparo Dos Sistemas Aquosos} Bifásicos

Para montagem do sistema aquoso bifásico, composto por PEG-Sal-água, serão preparadas soluções estoque de PEG em água e Sal em água. A solução de sal foi preparada colocando quantidades adequadas do fosfato de potássio monobásico e bibásico, a fim de obter os pHs desejados.

Os diagramas de fase dos sistemas aquosos foram formados utilizando soluções aquosas de PEG 2000 + Sal + água, PEG $6000+$ Sal+ água, na temperatura de $5^{\circ} \mathrm{C}$ e nos pHs 6 e 7. Esses sistemas serão construídos pela aplicação do método turbimétrico (ALBERTSSON, 1986), que indica $\mathrm{o}$ início da região bifásica. $\mathrm{O}$ procedimento consiste em pesar $1 \mathrm{~g}$ da solução de PEG em tubos de vidro, para melhor visualização da turvação. $O$ tubo contendo a solução de PEG será levado ao banho termostático e deixado até atingir o equilíbrio térmico. Em seguida, serão adicionadas gota a gota da solução de sal $(50 \mu \mathrm{L})$ com auxílio de uma pipeta automática, até ocorrer à turvação do sistema (solução bifásica). Nesse momento deverá ser registrada a quantidade de LI que provocou a turvação. Em seguida, o sistema deverá ser titulado com água destilada até o desaparecimento da turvação, registrando o seu valor. Esse procedimento deverá ser repetido continuamente até a obtenção dos pontos necessários para fazer a curva.

A equação empírica (Equação 1) foi utilizada para correlacionar os dados das binodais (WANG et al., 2010).

$\mathrm{w}_{1}=\exp \left(\mathrm{a}+\mathrm{b} \mathrm{w}_{2}{ }^{0,5}+\mathrm{cw}_{2}+\mathrm{dw}_{2}{ }^{2}\right)$
Onde w1 é a fração mássica de polietilenoglicol, w2 é a fração mássica de sal e a, b, c e d são parâmetros de ajuste da equação.

\subsubsection{Determinação das Linhas de Amarração}

A partir das binodais, serão preparados três pontos globais para cada condição estudada. Foram utilizados três pontos globais para cada sistema PEG-sal, os quais estão apresentados na tabela 1. Os sistemas forma formados com adição de quantidade adequada de solução estoque de PEG, sal e água em balança analítica até que se alcance uma massa final de $50 \mathrm{~g}$, em tubos de centrifuga graduados, com fundo cônico. Após a montagem do sistema, os mesmos serão centrifugados durante 5 min a $4000 \mathrm{~g}$, para acelerar a formação de fase. Em seguida, os sistemas permanecerão em repouso em estufa B.O.D. por 24 horas para que o equilíbrio seja alcançado.

Tabela 1 - Composições globais para os sistemas formados por PEG 6000 + fosfato de potássio, nos pHs 6 e 7 e na temperatura de $5^{\circ} \mathrm{C}$, expressas em porcentagem mássica $(\% \mathrm{~m} / \mathrm{m})$

\begin{tabular}{lll}
\hline Ponto Global & PEG & sal \\
\hline 1 & 12 & 12 \\
2 & 14 & 14 \\
3 & 16 & 16 \\
\hline
\end{tabular}

Fonte: Próprio autor.

O comprimento da linha de amarração (CLA) e a inclinação da linha de amarração (ILA) foram calculados utilizando as equações 2 e 3 .

$$
\begin{aligned}
& \mathrm{CLA}=\left[(\mathrm{Cps}-\mathrm{Cpi})^{2}+(\mathrm{Css}-\mathrm{Csi})^{2}\right]^{0,5} \\
& \mathrm{ILA}=(\mathrm{Cps}-\mathrm{Cpi}) /(\mathrm{Css}-\mathrm{Csi})
\end{aligned}
$$

Onde: Cps e Cpi são as concentrações do polímero na fase superior e inferior, 
respectivamente, enquanto Css e Csi são as concentrações de sal na fase superior e inferior, respectivamente.

\subsubsection{Coleta de Fases}

Após alcançar o equilíbrio, as fases do topo e do fundo foram separadas e pesadas, utilizando seringas longas. As fases superiores foram retiradas com cuidado, deixando uma camada de $0,5 \mathrm{~cm}$ acima da interface. Posteriormente, uma seringa oi introduzida delicadamente para retirada da fase inferior no tubo, evitando a perturbação da interface. As fases foram armazenadas em recipientes com tampa e mantidos sob refrigeração o momento de realização das análises.

\subsubsection{Medida do Volume das Fases}

Foi obtida uma relação entre a massa de água e a altura da coluna de água atingida por essa massa. A partir da densidade da água, na temperatura ambiente, foi construída a curva analítica em função do volume de água e da altura da coluna de água utilizando a equação 4. Assim sendo, antes da retirada das alíquotas das fases, a altura de cada fase foi medida com auxílio de uma régua, para cálculo do volume. A altura da fase inferior foi lida a partir do fundo do tubo até a interface, e a altura da fase superior foi calculada subtraindo a medida da altura total (medida do fundo até a superfície da fase superior) com a medida da altura da fase inferior.

$\rho=m / v$

Onde: $\rho=$ densidade; $m=$ massa; $v=$ volume.

\section{RESULTADOS}

\subsection{Efeito da pH nos Diagramas Estudados}

A figura 1 mostra o diagrama de fases do sistema composto por PEG 6000 e fosfato de potássio nos pHs 6 e 7, na temperatura de $5^{\circ} \mathrm{C}$. Esses diagramas delineiam $\mathrm{O}$ comportamento dos sistemas aquoso bifásico e são únicos para cada sistema em condições de temperatura, concentração de sal e concentração do polímero, sendo que a formação das duas fases aquosas depende da concentração de do sistema. Abaixo das concentrações críticas do polímero e do sal, mistura dos componentes são completamente miscíveis formando uma fase homogênea; e, acima das concentrações críticas de PEG e sal, ocorre um sistema com duas fases. Sendo assim, o diagrama de fases separa a região monofásica (abaixo da curva) da bifásica (acima da curva) de acordo com a concentração de cada componente expressa em $\% \mathrm{~m} / \mathrm{m}$. Observa-se que ao se reduzir o $\mathrm{pH}$ de 7 para 6 é necessário aumentar a concentração dos constituintes das fases para construção da curva binodal. Tal resultado está de acordo a diversos trabalhos da literatura, como o de Ferreira et al. (2007), que estudou a influência do $\mathrm{pH}$ nos diagramas de fases constituídos por PEG 6000 e cloreto de cálcio e Videira e Aires-Barros (1994), que estudou o sistema formado por PEG/Fosfato nos $\mathrm{pHs} 7$ e 8 .

Figura 1 - Diagramas de equilíbrio de fases para sistemas PEG 6000, fosfato de potássio e água nos pHs 6 e 7 , na temperatura de $5^{\circ} \mathrm{C}$.

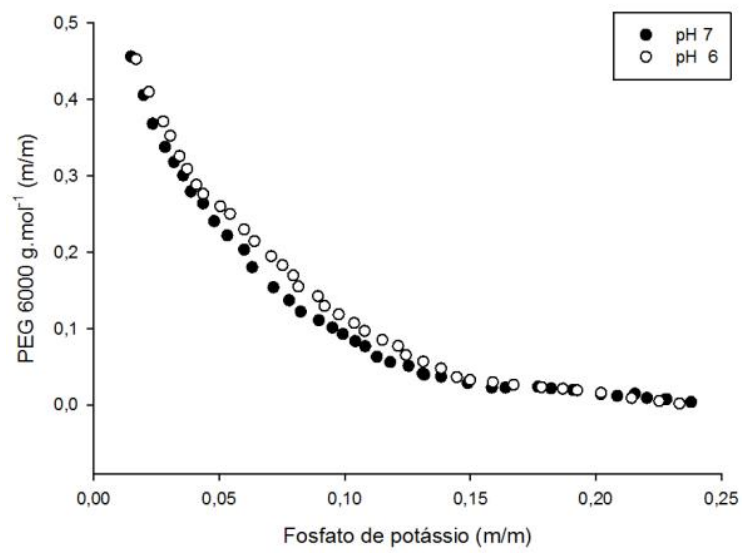


Fonte: Dados da pesquisa.

\subsection{Parâmetros Ajustados}

Os valores obtidos para os parâmetros $a, b, c$ e d da equação com seus respectivos desvios padrões e os coeficientes de determinação $\mathrm{R}^{2}$ das equações ajustadas para os sistemas investigados estão apresentados na Tabela 2.

Tabela 2 - Parâmetros ajustados e coeficiente de determinação $\left(\mathrm{R}^{2}\right)$ obtidos para o sistema PEG-sal pela equação de Hu et al., (2003)

\begin{tabular}{ccccc}
\hline \multirow{2}{*}{ Parâmetros } & & \multicolumn{2}{c}{$\mathrm{pH}$} \\
\cline { 1 - 1 } $\mathrm{a}$ & & 0,1669 & & $-0,3064$ \\
$\mathrm{~b}$ & & $-9,2008$ & & $-2,9373$ \\
$\mathrm{c}$ & & 15,8429 & & $-8,4689$ \\
$\mathrm{~d}$ & & $-99,9521$ & & $-32,9831$ \\
$\mathrm{R}^{2}$ & & 0,9986 & & 0,9986 \\
\hline
\end{tabular}

Fonte: Dados da pesquisa.

\subsection{Linhas de Amarração}

Foram determinadas três linhas de amarração para cada sistema estudado (Figuras 3 e 4). As composições globais e de equilíbrio, da fase superior e da fase inferior, dos SAB's formados por PEG 6000 e fosfato de potássio e água nos pHs 6 e 7 à $5^{\circ} \mathrm{C}$ são mostradas na tabela 3 e 4 .

Tabela 3 - Frações mássicas $(\% \mathrm{~m} / \mathrm{m})$ para sistemas formados PEG 6000 e fosfato de potássio e água nos pHs 6 à $5^{\circ} \mathrm{C}$

\begin{tabular}{|c|c|c|c|}
\hline LA & \multicolumn{3}{|c|}{ Composição Global do Sistema } \\
\hline & Wpeg & Wsal & Wágua \\
\hline 1 & 0,2411 & 0,4801 & 0,2788 \\
\hline 2 & 0,2803 & 0,5608 & 0,1591 \\
\hline \multirow[t]{3}{*}{3} & 0,3208 & 0,6401 & 0,3932 \\
\hline & \multicolumn{3}{|c|}{ Composição da Fase superior } \\
\hline & Wpeg & Wsal & Wágua \\
\hline 1 & 0,2210 & 0,0609 & 0,7181 \\
\hline 2 & 0,2788 & 0,0452 & 0,6760 \\
\hline \multirow[t]{3}{*}{3} & 0,3156 & 0,0370 & 0,6474 \\
\hline & \multicolumn{3}{|c|}{ Composição da Fase Inferior } \\
\hline & Wpeg & Wsal & Wágua \\
\hline
\end{tabular}

\begin{tabular}{llll}
\hline 1 & 0,0157 & 0,1811 & 0,8032 \\
2 & 0,0024 & 0,2340 & 0,7636 \\
3 & 0,0002 & 0,2863 & 0,7135 \\
\hline
\end{tabular}

Fonte: Dados da pesquisa

Tabela 4 - Frações mássicas $(\% \mathrm{~m} / \mathrm{m})$ para sistemas formados PEG 6000 e fosfato de potássio e água nos pHs 7 à $5^{\circ} \mathrm{C}$

\begin{tabular}{lllll}
\hline \multirow{2}{*}{ LA } & \multicolumn{3}{l}{ Composição Global do Sistema } \\
\cline { 3 - 5 } & & Wpeg & Wsal & Wágua \\
\hline 1 & & 0,2413 & 0,4834 & 0,2753 \\
2 & & 0,2803 & 0,5604 & 0,1593 \\
3 & & 0,3223 & 0,6414 & 0,0363 \\
& \multirow{2}{*}{ LA } & \multicolumn{4}{l}{ Composição da Fase superior } \\
\cline { 3 - 5 } & & Wpeg & Wsal & Wágua \\
\hline 1 & & 0,2692 & 0,0421 & 0,6887 \\
2 & & 0,3275 & 0,0314 & 0,6411 \\
3 & & 0,4039 & 0,0201 & 0,5760 \\
& \multirow{2}{*}{ LA } & \multicolumn{2}{l}{ Composição da Fase inferior } \\
\cline { 3 - 5 } & & Wpeg & Wsal & Wágua \\
\hline 1 & & 0,0106 & 0,1924 & 0,7970 \\
2 & & 0,0037 & 0,2317 & 0,7646 \\
3 & & 0,0016 & 0,2535 & 0,7449 \\
\hline
\end{tabular}

Fonte: Dados da pesquisa

Quando se traça a linha de amarração, verifica-se o alinhamento dos pontos relativos às fases e a mistura global.

Pode ser observado nas tabelas 3 e 4 que a fração mássica do fosfato de potássio é maior na fase inferior, e a fração mássica de PEG 6000 é maior na fase superior. Pode ser observado também que as frações mássicas de água nas duas fases são próximas.

De acordo com Da Silva e Loh (2006), o comprimento da linha de amarração está associado à seletividade do sistema. Quanto menor comprimento da linha de amarração (CLA), associada a uma dada composição global do sistema, mais próximo de 1 será o valor do coeficiente de partição da biomolécula de interesse, portanto, menos seletiva a extração. Entretanto com o aumento do CLA, a transferência da proteína tende a uma das fases, isto é, o valor do coeficiente de partição torna-se mais distantes de 1, para mais ou para menos. Esse comportamento é resultado do aumento na diferença da composição entre as fases que gera, consequentemente, o incremento das 
contribuições entrópicas e entálpicas na transferência da proteína para uma das fases.

De acordo com Carvalho (2004) a inclinação da linha de amarração é uma medida de como a composição das fases variam com a modificação de propriedades do sistema. Pode ser observado na tabela 4 que com o aumento do CLA para o sistema a pH 6 ocorreu um aumento na inclinação da linha de amarração (ILA). Para ph 7 tal comportamento não foi observado.

Tabela 4 - Dados do comprimento da linha de amarração (CLA) e inclinação da linha de amarração (ILA).

\begin{tabular}{llc}
\hline LA & \multicolumn{2}{c}{$\mathrm{pH} \mathrm{6}$} \\
\cline { 2 - 3 } 1 & CLA & ILA \\
2 & 0,2379 & $-1,7087$ \\
3 & 0,3348 & $-1,4640$ \\
& 0,4021 & $-1,2650$ \\
1 & & $\mathrm{pH} 7$ \\
2 & 0,2992 & $-1,7204$ \\
3 & 0,3808 & $-1,6163$ \\
\hline
\end{tabular}

Fonte: Dados da pesquisa

Figura 2 - Linhas de amarração para o sistemas formado por PEG 6000 + Fosfato de Potássio no pH 6 e na temperatura de $5^{\circ} \mathrm{C}$.

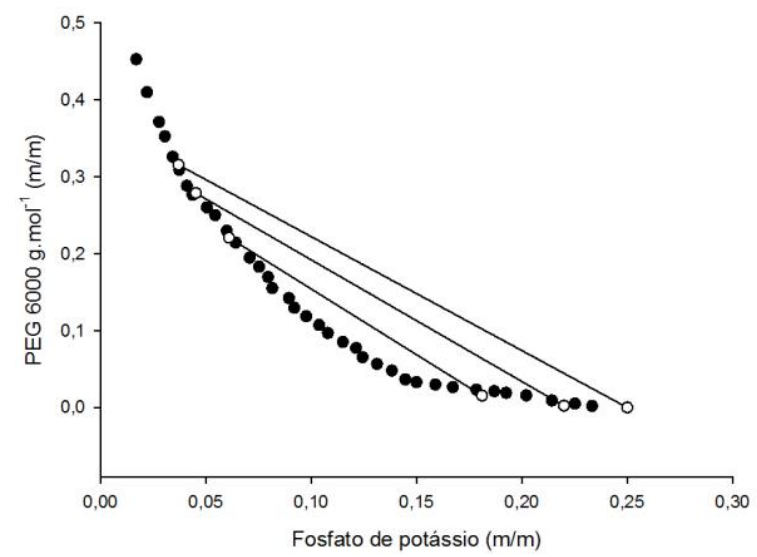

Fonte: Dados da pesquisa

Figura 3 - Linhas de amarração para o sistemas formado por PEG 6000 + Fosfato de Potássio no $\mathrm{pH} 7$ e na temperatura de $5^{\circ} \mathrm{C}$.

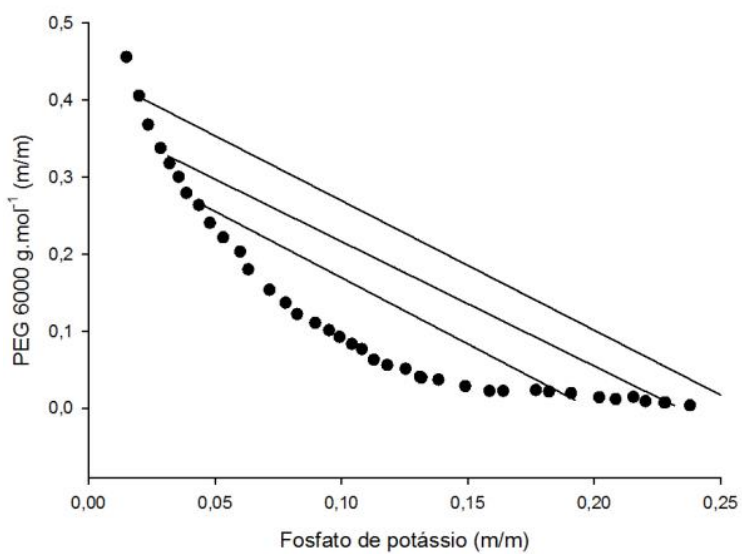

Fonte: Dados da pesquisa

\section{CONCLUSÃO}

Foi possível a construção das binodais para sistemas aquosos bifásicos compostos por polietilenoglicol (PEG), fosfato de potássio e água nas condições estudadas. Constatou-se que o aumento do $\mathrm{pH}$ favoreceu um aumento da área bifásica, além de aumentar o CLA e diminuir a ILA.

\section{NOMENCLATURA}

PEG - polietilenoglicol;

SAB - sistema aquoso bifásico;

$\mathrm{W}_{\mathrm{PEG}^{-}}$fração mássica de polietilenoglicol;

$\mathrm{W}_{\mathrm{SAl}}$ - fração mássica de sal;

CLA - comprimento da linha de amarração;

ILA - inclinação da linha de amarração;

a, b, c e d - parâmetros de ajuste da equação;

Cps - concentração do polímero na fase superior;

Cpi - concentração do polímero na fase inferior;

Css - concentração de sal na fase superior;

Csi concentração de sal na fase inferior

$\rho=$ densidade;

$m=$ massa;

$v=$ volume. 


\section{REFERÊNCIAS}

ALBERTSSON, P.A. Partition of cell and macromolecules. New York: John Wiley, 1986, 346p.

AMID, M.; SHUHAIMI, M.; SARKER, Md. Z. I.; MANAP, M. Y. A. Purification of serine protease from mango (Mangifera indica $\mathrm{Cv}$. Chokanan peel using an alcohol/salt aqueous two phase system. Food Chemistry, v.132, p.1382-1386, 2012.

CARVALHO, C.P. Estudo do Equilibrio de Fases para Sistemas Aquosos Bifasicos Compostos por Poli (Etileno) Glicol, Sais e Água. 2004. 70 f. Dissertação (Mestrado em Ciencia e Tecnologia de Alimentos) Departamento de Tecnologia de Alimentos, Universidade Federal de Vicosa, 2004.

CARVAlHO, C. C.; COIMBRA, J. S. R.; COSTA, I. A. F.; MINIM, L. H.; MAFFIA, M. C. Equilibrium Data for PEG $4000+$ Salt + Water Systems from (278.15 to 318.15). Journal Chemical \& Engineeting Data, v.52, p.351-356, 2007.

DA SILVA, L. H. M. LOH, W. Sistemas aquosos bifásicos: fundamentos e aplicações para partição/purificação de proteínas. Química Nova, v.29, p.1345-1351, 2006.

FERREIRA, G. B.; EVANGELISTA, A. F.; JUNIO, J. B.S.; SOUZA, R. R.; CURVELO SANTANA, J. C.; TAMBOURGI, E. B.; JORDÃO, E. Partitioning Optimization of Proteins from Zea mays Malt in ATPS PEG 6000/CaCl2. Brazilian Archives of Biology and Technology, v. 50, p. 557-564, 2007.

GARZA-MADRID, $\quad$ M.; $\quad$ RITOPALOMARES, M.; SERN-SALDÍVAR, S. O.; BEMAVIDES, J. Potential of aqueous two-phase system construted on flexible devices: human serum albumin as proof of concept. Process Biochemistry, v.45, p.10821087, 2010.

LOUROS, C. L. S.; CLÁUDIO, A. F. M.; NEVES, C. M. S. S.; MARRUCHO, M. G. F.; ISABEL M.; PAULY, J.; COUTINHO, J. A. P.; A Extraction of Biomolecules Using Phosphonium-Based IonicLiquids $+\mathrm{K}_{3} \mathrm{PO}_{4}$ Aqueous Biphasic Systems. International Journal of Molecular, v.11, p.1777-1791, 2010.

HUSTED, H. CORNER, K. H.; KULA, M. R. Partition in aqueous two-phase systems. Trends Biotech, v.3, p. 139-144, 1985.

SAKABAT, A. The influence of salt on the phase composition in aqueous two-phase systems: experiments and prediction. Fluid Phase Equilibria, v.187-188, p.489-498, 2001.

SAMPAIO, V. S. Obtenção de dados de equilíbrio termodinâmico, densidade e viscosidade de sistemas aquosos bifásicos constituídos de polietilenoglicol e poliacrilato de sódio. 45f. Dissertação (Mestrado em Engenharia de Alimentos) Departamento de Tecnologia de Alimentos, Universidade Estadual do Sudoeste da Bahia, 2012.

VIDEIRA, M.; AIRES-BARROS, M. R. Liquid-liquid extracion of clavulanic acid using na aqueous two-phase system of polyethylene glycol and potassium phosphate. Journal of Chromatografy A, v. 668, p. 237-240, 1994. 